\title{
Beliefs and Attitudes Associated With Hookah Smoking Among a United States College Population
}

\author{
Mary P Martinasek PhD RRT, Linda G Haddad RN PhD, Christopher W Wheldon PhD, \\ and Tracey E Barnett PhD
}

\begin{abstract}
BACKGROUND: This study explores the differences among smokers of waterpipe tobacco in a college population to better inform campaigns to curb waterpipe use. METHODS: Participants included undergraduate and graduate students attending a liberal arts university in Florida. E-mail-based, cross-sectional surveys were collected in 2 sequential years. RESULTS: The majority of respondents (64\%) reported having ever smoked a hookah, even if just 1-2 puffs. Of those who had ever smoked a hookah, $34 \%$ reported smoking a hookah within the previous $30 \mathrm{~d}$. Constructs from the theory of reasoned action were all correlated with smoking behavior. The range of beliefs endorsed by smokers were more strongly associated with hookah-related attitudes compared with subjective norms. Concerns about health were stronger among never-smokers. CONCLUSIONS: Young adult college students continue to engage in waterpipe tobacco smoking at high rates. Campaigns need to focus on subsets of smokers and nonsmokers, independently. Key words: hookah smoking; waterpipe tobacco smoking; college students; theory of reasoned action; shisha; attitudes; subjective norm; behavior. [Respir Care 2017;62(3):370-379. () 2017 Daedalus Enterprises]
\end{abstract}

\section{Introduction}

Waterpipe tobacco smoking is among the fastest growing trends in tobacco smoking, the growing use and acceptance of which is taking place at a time when cigarette smoking is regarded in an increasingly negative manner. ${ }^{1}$ Due to its more recent introduction into the United States, the majority of waterpipe studies have been conducted in the Middle East, where the waterpipe has strong cultural

\footnotetext{
Dr Martinasek is affiliated with the Department of Health Sciences and Human Performance, University of Tampa, Tampa, Florida. Dr Haddad is affiliated with the College of Nursing, University of Florida, Gainesville, Florida 32610. Dr Wheldon is affiliated with the Department of Community and Family Health, University of South Florida, Tampa, Florida. Dr Barnett is affiliated with the Department of Epidemiology, College of Public Health and Health Professions, College of Medicine, University of Florida, Gainesville, Florida.
}

The authors have disclosed no conflicts of interest.

Correspondence: Mary P Martinasek PhD RRT, Department of Health Sciences and Human Performance, University of Tampa, $401 \mathrm{~W}$ Kennedy Boulevard, Box 30F, Tampa, FL 33606. E-mail: MMartinasek@ut.edu.

DOI: $10.4187 /$ respcare.05069 roots. ${ }^{2-9}$ Few United States studies have examined the initiation and pattern of waterpipe tobacco smoking measured at a single point in time using a theoretical model and accounting for differences among types of waterpipe smokers. ${ }^{10-14}$ Collectively, these studies have reported that waterpipe tobacco smoking has higher social approval than cigarette use and is perceived as less harmful and addictive than cigarette smoking. The studies also found that waterpipe tobacco smoking was positively associated with cigarette smoking. The United States tobacco control community is rightfully concerned that the waterpipe will have a gateway effect and undermine the advances in tobacco reduction among youth achieved in the past 30 years. Health messages in communities, college campuses, and health-care settings on waterpipe tobacco smoking are nonexistent as compared with traditional cigarette smoking health messages; therefore, waterpipe tobacco smoking is regarded as more socially acceptable than cigarette smoking, especially among young women. ${ }^{12,15,16}$ For the respiratory field, understanding how to use a theoretical model to understand predictors of smoking can be helpful in conducting research in any population. This study may benefit the respiratory field by suggesting that interventions are needed from clinicians and community health workers. Clinic/hospital intake sheets should include waterpipe to- 
bacco smoking so that education on the ill effects of this behavior can be addressed with the client. Data are prevalent on both the acute and chronic effects of hookah smoking. In particular, hookah smoking contributes to high levels of carbon monoxide, resulting in health-care costs for this preventable behavior. Long-term effects include lung cancer. Additionally, interventions such as motivational interviewing, commonly used with smoking cessation programs, can encourage behavior change from negative to positive health behaviors regarding hookah smoking. Clinicians and health-care workers can also consider educating their patients on the deleterious effects of hookah smoking through flyers and pamphlets where other educational materials are located.

One explanation for the popularity of hookah smoking is that waterpipe cafés or bars, unlike traditional bars, do not adhere to age restriction policies on those $<21$ y old. It is likely that the lack of adherence is due to the limited alcohol served on the premises. This feature attracts many young adults who want to have a social outing with friends but are not old enough to enter a traditional bar. Waterpipe bars or cafés provide the same social atmosphere but typically without alcohol; the communal waterpipe is the conduit for social interaction. Waterpipe tobacco smoking is a widely accepted social activity that is viewed as being cool. ${ }^{17-19}$ This may increase the number of individuals who try a waterpipe and who expose themselves to the secondhand smoke in a café/bar setting. A British study found that waterpipe tobacco smoking increased with time spent in college, whereas the highest level of smoking cigarettes occurred during the first year of school and then decreased. The same study found that $83.9 \%$ of college students were introduced to waterpipe tobacco smoking by a friend, which is likely to occur in the United States because the number of waterpipe cafés has increased. ${ }^{20}$

Waterpipe tobacco smoking is also popular among young adults because it is relatively inexpensive. ${ }^{21}$ Likewise, waterpipe tobacco smoking is increasing due to a combination of greater spare time and disposable income, both of which have been associated with waterpipe tobacco smoking. Three studies $22-25$ found that social context, in the form of social networking and technology (eg, Twitter, Facebook) also had a big impact on the popularity of waterpipe tobacco smoking. It is logical that young adults with more disposable income and free time will be more likely to own technological devices, such as computers and smart phones, with large data contracts that allow them to generate more social contacts.

Several studies have examined the perceived health risks, particularly among young adults who smoke waterpipes.7,11,26,27 Although many communities have banned traditional cigarette smoking in public areas, bars, and restaurants, the mere presence of a waterpipe café conveys that waterpipe tobacco smoking is an exception. Thus, the

\section{QUICK LOOK}

\section{Current knowledge}

Waterpipe tobacco smoking, also known as hookah smoking, has been shown to produce acute short-term health issues, such as carbon monoxide toxicity, and long-term effects, such as oral cancers. Perceptions of the safety of waterpipe tobacco smoking continue to remain prevalent among young adults.

\section{What this paper contributes to our knowledge}

Understanding the theoretical underpinnings of the intention to smoke waterpipe tobacco can help to curb waterpipe tobacco smoking. The influence of beliefs regarding safety and lack of harm to one's health directly inform attitudes that are a strong predictor of the intention to smoke. Negative attitudes dissuade usage, whereas positive attitudes encourage usage. Information gained from a priority population can be used to develop messages and behavior change campaigns.

average person may assume that waterpipe tobacco smoking is simply not equivalent to "smoking" and not harmful like cigarettes or cigars. This message is reinforced when the business prominently displays, as required, their current health inspection score from the local health department.

Personal factors also are a strong predictor in waterpipe smoking initiation and use. A recent cross-sectional study in the United States examined how personal factors might contribute to waterpipe tobacco smoking. ${ }^{28}$ Positive attitudes toward waterpipe tobacco smoking were related to its sweet smell and pleasant taste. As a result, many young adults may view waterpipe tobacco smoking as an appealing way to spend leisure time socializing with friends. Using the theory of reasoned action, ${ }^{29}$ other investigators have examined the intrapersonal variables of attitudes, behavioral beliefs, and subjective norms related to waterpipe tobacco smoking. These variables collectively explained $34 \%$ of the variance in intention to smoke a waterpipe within the next 3 months. Demographic characteristics (sex, race, year in school) and other tobacco variables (current waterpipe tobacco use and current traditional cigarette use) explained $82 \%$ of the variance in intention to smoke a waterpipe within the next 3 months. Positive intention regarding waterpipe tobacco smoking was a significant predictor of actual waterpipe tobacco smoking at 3 months and explained $50 \%$ of the variance in actual waterpipe tobacco smoking. ${ }^{11,30}$ These data confirm the value of the theory of reasoned action for providing a substantial explanation for waterpipe tobacco smoking and identifying predictive variables in this population. ${ }^{11,30}$ 


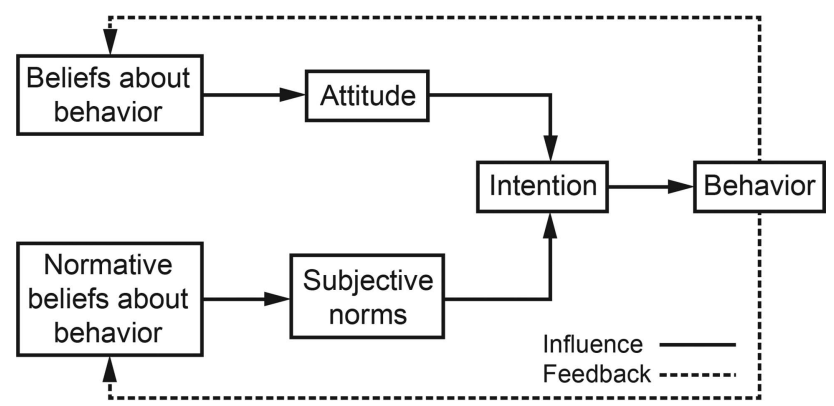

Fig. 1. Theory of reasoned action.

The theory of reasoned action was utilized to shape our study design, identify our measures, and direct our statistical analyses (Fig. 1). The theory of reasoned action describes the conceptual pathway in personal decision making about waterpipe tobacco smoking behavior, which is ultimately predicted by an individual's intention to perform the behavior. Intention is a function of 2 factors: the individual's attitude toward waterpipe tobacco smoking and the individual's subjective perception of waterpipe tobacco smoking. Both attitudes and norms are formed on the basis of sets of beliefs: beliefs regarding the consequences of waterpipe tobacco smoking (behavioral belief) and what significant others believe about waterpipe tobacco smoking (normative belief). Attitudes are further impacted by evaluation of outcomes of waterpipe tobacco smoking; subjective norms are also affected by motivation to comply or participate in waterpipe tobacco smoking.

There are insufficient data regarding differences in beliefs regarding waterpipe tobacco smoking between eversmokers and current smokers and limited data on differences in demographic variables, attitudes, subjective norms, and intention specifically between ever-smokers and current waterpipe smokers. Therefore, this study was conducted with 2 aims: (1) to examine the differences in demographic variables, attitudes, behavioral beliefs, subjective norms, and behavioral intention in young adult waterpipe smokers based on smoking status (ever or current) and (2) to determine whether demographic variables, beliefs, and ever smoking significantly predict the attitudes and subjective norms among waterpipe non-smokers, current smokers, and ever-smokers.

\section{Methods}

\section{Participants and Procedures}

The present study used a cross-sectional survey to assess waterpipe tobacco smoking use at an independent liberal arts university in Florida. The university is situated in a metropolitan downtown Tampa area. The university is a mid-sized residential university with a student popula- tion of around 8,000 undergraduate and graduate students. E-mail addresses were obtained from the university's office of institutional effectiveness. The survey was sent via e-mail invitation by the primary investigator requesting participation.

Consent for the study was achieved by describing the study in the recruitment e-mail. If participants voluntarily agreed to participate in the study, they were requested to click on an external link, which directed them to the online survey. The recruitment e-mail for the cross-sectional online survey assessing waterpipe use was sent to all undergraduate students attending the University of Tampa in the fall of 2011 and repeated in the fall of 2012. Both waterpipe smokers and nonsmokers were invited to complete the survey. Data were collected for 2 weeks mid-fall semester to avoid holidays and summer days. Incentives to participate each year included a drawing for one of $10 \$ 50$ gift cards. Gift cards were distributed by collecting e-mail addresses of participants at the end of the survey. The e-mail addresses were then numbered in accordance with the survey completion, and a drawing using a random number generator was utilized to distribute the gift cards. The survey instrument was designed by the first author utilizing the theory of reasoned action, which provided a validated tool for assessing the theoretical constructs. ${ }^{31}$ Inclusion criteria consisted of students who were currently attending the University of Tampa and were $>17$ y old.

The data sets were combined, and duplicate survey data were removed based on e-mail addresses of participants. E-mail addresses were removed from the data before data analysis. This accounted for the removal of 89 participants in the 2012 survey data. The final sample size for the combined data set was 1,539 participants. Listwise deletion was used to remove cases with missing data, therefore tables may represent smaller sample sizes. All studies were approved by the institutional review board at the University of Tampa before study commencement. Survey data were stored on a password-protected computer.

\section{Measurements}

The self-report questionnaires consisted of 5 major components.

Ever-Smoker Versus Current Smoker. To assess the difference between ever and current waterpipe tobacco smoking, the following questions were asked: "Have you ever tried smoking tobacco from a hookah, even 1 or 2 puffs?" for assessing the prevalence of ever-smokers and "During the past $30 \mathrm{~d}$, have you smoked hookah, even 1 or 2 puffs?" for capturing current smoker prevalence.

Intention to Smoke a Hookah. Intention to smoke, which is the first theory of reasoned action construct, was as- 
sessed by having participants complete the following statement: "Regarding your intention to smoke hookah, I intend to smoke hookah in the next 3 months ..." (with a 7-point Likert scale ranging from extremely unlikely to extremely likely).

Attitudes. Attitude toward waterpipe tobacco smoking, which is the second theory of reasoned action construct, was assessed using 2 primary statements with 7-point Likert scales. The following statements included: "If I smoke hookah, the behavior is ..." and "For me, smoking hookah is ..." (with a 7-point Likert scale ranging from "extremely bad to extremely good," "extremely awful to extremely nice," "extremely not fun to extremely fun," and "extremely unpleasant to extremely pleasant."

Subjective Norms. Subjective norms, the third theory of reasoned action construct, were assessed by providing the following single statement: "If I smoke hookah, most of the people who are important to me would ..." with a 7-point Likert scale ranging from "extremely disagree" to "extremely agree."

Beliefs. Belief assessment, which is the fourth theory of reasoned action construct, was categorized into 6 domains. Response categories included physical, mental, social, recreational, cultural, and health. The participants were asked to provide their beliefs and opinions on 22 statements with a 7-point Likert scale ranging from "extremely unlikely" to "extremely likely." For the physical construct, items included: relaxation, buzz, legal high, and relief of stress. For the social construct, items included: meet a date, be social, and make new friends. For the recreational construct, items included fun and passing time. For the cultural construct, items included bringing family together and culture. For the health belief, items included cough, headache, cancer, chest pain, addiction, dizziness, shortness of breath, infectious disease, and harm perception. Mental beliefs included staying focused, thinking clearly, and intellect.

\section{Analysis}

SAS 9.4 statistical software (SAS Institute, Cary, North Carolina) was used to conduct all analyses. ${ }^{32}$ Descriptive statistics were calculated to characterize the study sample in terms of sociodemographic variables and psychosocial indicators of waterpipe tobacco smoking-related attitudes, behavioral beliefs, subjective norms, and behavioral intention. The sample was stratified for the following comparisons: (1) respondents who had never smoked a hookah compared with those who had ever smoked a hookah and (2) respondents who smoked in the previous $30 \mathrm{~d}$ (current smokers) compared with those who had smoked but not within the previous $30 \mathrm{~d}$ (ever-smokers).

These comparisons were explored using chi-square analysis of independence for categorical variables (eg, demographic variables) and independent samples $t$ tests for interval level variables (eg, psychosocial variables). Point biserial correlations were used to characterize the differences in hookah-related behavioral beliefs across 6 domains of beliefs (ie, physical benefits, mental benefits, social benefits, recreational benefits, cultural benefits, and health consequences). Items within each domain were averaged to create composite variables that were used in regression analysis.

Multiple hierarchical linear regression was used to assess the ability of demographic characteristics, previous smoking behaviors, and hookah-related beliefs to explain variation in hookah attitudes and subjective norms. Changes in the coefficient of determination $\left(\Delta \mathrm{R}^{2}\right)$ were used to evaluate fit over 3 nested models. Finally, zero-order correlations were used to evaluate the associations between key constructs from the theory of reasoned action stratified by waterpipe tobacco smoking history.

\section{Results}

The final data set consisted of a sample size of 1,539 participants representing a response rate of $13 \%$. The total data set represented students with ages ranging from 18 to $23 \mathrm{y}$. The majority of the participants were $18-19 \mathrm{y}$ old $(51.3 \%)$, probably representing freshmen and sophomores at the university. Participants were primarily nonHispanic as indicated by a separate question assessing Hispanic versus non-Hispanic (85.7\%) and white ethnicity $(77.5 \%)$. Female respondents represented $69.8 \%$ of the sample.

\section{Differences in Demographic Variables, Attitudes, Behavioral Beliefs, Subjective Norms, and Behavioral Intention Among Waterpipe Ever-Smokers or Current Smokers}

Students were subdivided into ever-smokers, those who had ever smoked a waterpipe (even 1 or 2 puffs), and current smokers, those who had reported waterpipe tobacco smoking in the past $30 \mathrm{~d}$. Comparisons were made within these 2 groups to examine the demographic variables. Statistical significance was set at $P=.05$.

As noted in Table 1, there was a statistically significant difference in the ages when examining both ever-smokers and current smokers and both groups of smokers tended to be younger. Also, non-United States citizen status was statistically significant $(P=.02)$ for current smokers only. When assessing age in both ever-smokers and current smok- 
Table 1. Demographic and Psychosocial Characteristics by Waterpipe Tobacco Smoking Behaviors

\begin{tabular}{|c|c|c|c|c|c|}
\hline Characteristics & $\begin{array}{l}\text { Total Sample } \\
(N=1,494)\end{array}$ & $\begin{array}{c}\text { Waterpipe } \\
\text { Ever-Smokers } \\
(n=950)\end{array}$ & $P^{*}$ & $\begin{array}{l}\text { Current Waterpipe } \\
\text { Tobacco Smokers } \\
\quad(n=324)\end{array}$ & $P \dagger$ \\
\hline \multicolumn{6}{|l|}{ Demographics, $n(\%)$} \\
\hline Age & & & $<.001$ & & $<.001$ \\
\hline 18 & $426(28.5)$ & $252(59.2)$ & & $119(47.2)$ & \\
\hline 19 & $340(22.8)$ & $204(60.0)$ & & $79(38.7)$ & \\
\hline 20 & $281(18.8)$ & $182(64.8)$ & & $53(29.4)$ & \\
\hline 21 & $234(15.7)$ & $171(73.1)$ & & $34(20.0)$ & \\
\hline 22 & $108(7.2)$ & $79(73.2)$ & & $23(29.1)$ & \\
\hline 23 & $105(7.0)$ & $62(59.1)$ & & $16(26.2)$ & \\
\hline Ethnicity & & & .72 & & .67 \\
\hline Hispanic & $213(14.3)$ & $133(62.4)$ & & $43(32.6)$ & \\
\hline Non-Hispanic & $1279(85.7)$ & $815(63.7)$ & & $280(34.5)$ & \\
\hline Race & & & .01 & & .45 \\
\hline White & $1143(77.5)$ & $749(65.5)$ & & $247(33.2)$ & \\
\hline Black & $117(7.9)$ & $58(49.6)$ & & $22(37.9)$ & \\
\hline Asian/Pacific islanders & $41(2.8)$ & $25(61.0)$ & & $7(28.0)$ & \\
\hline American Indian & $8(0.5)$ & $4(50.0)$ & & $2(50.0)$ & \\
\hline Other & $165(11.2)$ & $105(63.6)$ & & $43(41.0)$ & \\
\hline Sex & & & .001 & & .047 \\
\hline Male & $448(30.3)$ & $327(73.0)$ & & $126(38.5)$ & \\
\hline Female & $1033(69.8)$ & $615(59.5)$ & & $196(32.1)$ & \\
\hline United States citizen & & & .16 & & .02 \\
\hline Yes & $1385(93.3)$ & $873(63.0)$ & & $290(33.4)$ & \\
\hline No & $100(6.7)$ & $70(70.0)$ & & $33(47.1)$ & \\
\hline Religion & & & .01 & & .006 \\
\hline No religion & $416(28.0)$ & $272(65.4)$ & & $100(36.9)$ & \\
\hline Catholic & $554(37.3)$ & $354(63.9)$ & & $110(31.2)$ & \\
\hline Protestant & $92(6.2)$ & $58(63.0)$ & & $19(33.3)$ & \\
\hline Other Christian & $260(17.5)$ & $146(56.2)$ & & $50(34.3)$ & \\
\hline Jewish & $51(3.4)$ & $41(80.4)$ & & $9(22.5)$ & \\
\hline Muslim & $20(1.3)$ & $16(80.0)$ & & $12(75.0)$ & \\
\hline Buddhist & $19(1.3)$ & $15(80.0)$ & & $3(20.0)$ & \\
\hline Other & $75(5.0)$ & $43(57.3)$ & & $19(44.2)$ & \\
\hline \multicolumn{6}{|c|}{ Continuous variables, mean $\pm \mathrm{SD}$} \\
\hline Attitudes & $3.7 \pm 1.6$ & $4.5 \pm 1.3$ & $<.001$ & $5.1 \pm 1.0$ & $<.001$ \\
\hline Subjective norms & $3.6 \pm 1.2$ & $4.0 \pm 1.0$ & $<.001$ & $4.4 \pm 1.1$ & $<.001$ \\
\hline Behavioral intention & $3.0 \pm 2.2$ & $3.8 \pm 2.2$ & $<.001$ & $5.4 \pm 1.9$ & $<.001$ \\
\hline
\end{tabular}

ers, a positive trend was noted in ever-smokers with age, such that as age increased, the percentage of smokers increased as well. Eighteen-year-olds represented $59.2 \%$ of ever-smokers, and 22-y-olds represented $73.2 \%$ of eversmokers. The opposite was found with current waterpipe smokers; as age increased, the percentage of current waterpipe smokers declined.

Furthermore, there were significant differences by racial identity. Among ever-smokers, the largest difference was between whites $(65.5 \%)$ and blacks $(49.6 \%)$ who had ever smoked. However, there were no statically significant dif- ferences in the prevalence of current smoking across racial groups.

Determination of Whether Demographic Variables, Beliefs, and Ever-Smoking Can Predict the Attitudes and Subjective Norms Among Waterpipe Ever-Smokers or Current Smokers

Based on the theory of reasoned action, immediate precursors to the intention to smoke include attitude and subjective norms. The mean scores of these variables were 
Table 2. Regression of Hookah Attitudes and Subjective Norms on Demographic Variables and Behaviors and Beliefs

\begin{tabular}{|c|c|c|c|c|}
\hline \multirow{3}{*}{ Variables } & \multicolumn{4}{|c|}{ Dependent Variable* } \\
\hline & \multicolumn{2}{|c|}{ Hookah Attitudes } & \multicolumn{2}{|c|}{ Subjective Norms } \\
\hline & Unstandardized Beta $(\beta)$ & Standardized Beta $(\beta)$ & Unstandardized Beta $(\beta)$ & Standardized Beta $(\beta)$ \\
\hline \multicolumn{5}{|l|}{ Step 1: Demographics } \\
\hline Age & -0.05 & -0.05 & -0.04 & -0.05 \\
\hline Hispanic/Latino & -0.03 & -0.01 & -0.18 & -0.05 \\
\hline Non-white race & -0.16 & -0.04 & $-0.31 \dagger$ & -0.11 \\
\hline Sex & $-0.32 \dagger$ & -0.09 & $-0.21 \dagger$ & -0.08 \\
\hline United States citizen & 0.02 & 0 & -0.14 & -0.03 \\
\hline \multicolumn{5}{|l|}{ Religion } \\
\hline \multicolumn{5}{|l|}{ Not religious (referent) } \\
\hline Catholic & -0.17 & -0.05 & -0.16 & -0.06 \\
\hline Other Christian & $-0.40 \dagger$ & -0.11 & $-0.32 \dagger$ & -0.11 \\
\hline Jewish & -0.11 & -0.01 & -0.05 & -0.01 \\
\hline Muslim & -0.45 & -0.03 & -0.43 & -0.04 \\
\hline Buddhist & 0.09 & 0.01 & -0.08 & -0.01 \\
\hline Other & -0.08 & -0.01 & -0.10 & -0.02 \\
\hline Adjusted $\mathrm{R}^{2}$ & 0.02 & & 0.03 & \\
\hline \multicolumn{5}{|l|}{ Step 2: Smoking behaviors } \\
\hline Ever smoked a hookah & $1.90 \dagger$ & 0.56 & $1.13 \dagger$ & 0.44 \\
\hline Regular cigarettes & $0.77 \dagger$ & 0.19 & $0.28 \dagger$ & 0.09 \\
\hline Adjusted $\mathrm{R}^{2}\left(\Delta \mathrm{R}^{2}\right)$ & $0.42(0.40) \ddagger$ & & $0.25(0.22) \S$ & \\
\hline \multicolumn{5}{|l|}{ Step 3: Hookah beliefs } \\
\hline Physical benefits & $0.14 \dagger$ & 0.14 & 0.01 & 0.02 \\
\hline Mental benefits & $0.08 \|$ & 0.06 & 0 & 0 \\
\hline Social benefits & 0 & 0 & 0.03 & 0.03 \\
\hline Recreation & $0.56 \dagger$ & 0.41 & $0.22 \dagger$ & 0.34 \\
\hline Cultural benefits & 0.09凹 & 0.07 & $0.11 \Phi$ & 0.10 \\
\hline Health consequences & $-0.27 \dagger$ & -0.20 & $-0.11 \dagger$ & -0.11 \\
\hline Adjusted $\mathrm{R}^{2}\left(\Delta \mathrm{R}^{2}\right)$ & $0.68(0.26)^{* *}$ & & $0.38(0.16) \dagger \dagger$ & \\
\hline $\begin{array}{l}N=1,440 . \\
* \text { Hookah attitudes and subjective } \mathrm{n} \\
\dagger P<.001 . \\
¥ \text { Change in } \mathrm{R}^{2} \text { between Steps } 1 \text { an } \\
\$ \text { Change in } \mathrm{R}^{2} \text { between Steps } 1 \text { an } \\
\| P<.05 \text {. } \\
\mathbb{I} P<.01 . \\
* * \text { Change in } \mathrm{R}^{2} \text { between Steps } 2 \text { a } \\
\dagger \dagger \text { Change in } \mathrm{R}^{2} \text { between Steps } 2 \text { a }\end{array}$ & $\begin{array}{l}\text { modeled separately. } \\
\text { atistically significant, } P<.001 \text {. } \\
\text { tatistically significant, } P<.001 \text {. } \\
\text { statistically significant, } P<.001 \text {. } \\
\text { statistically significant, } P<.001 \text {. }\end{array}$ & & & \\
\hline
\end{tabular}

assessed for differences between current waterpipe smokers and ever-smokers. A step-wise regression analysis was conducted to further assess the effects of demographic characteristics, waterpipe tobacco smoking behaviors, and beliefs on the immediate predictors of intention: subjective norms and attitude.

Little difference was noted between the 2 constructs when regressing demographics (adjusted $\mathrm{R}^{2}$ for subjective norms $=0.03$ and for attitude $=0.02$ ) (Table 2). However, when ever-smoking and traditional cigarette use were added to the model, the adjusted $\mathrm{R}^{2}$ value for attitude increased to 0.42 , and that for subjective norms increased to 0.25 . This added step in the model served to increase both adjusted $\mathrm{R}^{2}$ values for attitude and subjective norm and also significantly increased the prediction of attitude as compared with the subjective norm.

Last, beliefs were regressed into the model and further increased the prediction of attitude (adjusted $\mathrm{R}^{2}=0.68$ ), with the primary correlates being physical benefits $(\beta=0.14)$, recreation benefits $(\beta=0.56)$, and health consequences $(\beta=-0.27)$. For subjective norms, adjusted $\mathrm{R}^{2}$ increased to 0.38 , with the greatest correlates being recreation $(\beta=0.22)$, cultural benefits $(\beta=0.11)$, and health consequences $(\beta=-0.11)$.

Specific beliefs of smoking behavior were assessed by mean scores for differences within ever-smokers (yes/no) and current smokers (yes/no) (Table 3). In particular, we assessed whether there were statistically significant differ- 
Table 3. Mean \pm SD and Associations of Waterpipe-Related Beliefs and Behaviors

\begin{tabular}{|c|c|c|c|c|c|c|c|c|}
\hline \multirow{2}{*}{ Beliefs } & \multicolumn{3}{|c|}{$\begin{array}{l}\text { Among the Full Sample (Ever- and } \\
\text { Never-Smokers), Ever Smoked a } \\
\text { Waterpipe }\end{array}$} & \multirow[t]{2}{*}{$\mathrm{r}^{*}$} & \multicolumn{3}{|c|}{$\begin{array}{c}\text { Among Those Who Ever Smoked } \\
\text { a Waterpipe, Current Waterpipe } \\
\text { Tobacco smoking }\end{array}$} & \multirow[t]{2}{*}{$\mathrm{r}^{\dagger}$} \\
\hline & $\begin{array}{c}\text { Yes } \\
(\text { Mean } \pm \mathrm{SD})\end{array}$ & $\begin{array}{c}\text { No } \\
(\text { Mean } \pm \mathrm{SD})\end{array}$ & $P$ & & $\begin{array}{c}\text { Yes } \\
(\text { Mean } \pm \text { SD) }\end{array}$ & $\begin{array}{c}\text { No } \\
(\text { Mean } \pm \text { SD })\end{array}$ & $P$ & \\
\hline \multicolumn{9}{|l|}{ Physical benefits } \\
\hline It will help me relax and relieve my stress & $3.71 \pm 1.90$ & $2.10 \pm 1.64$ & $<.001$ & 0.39 & $4.51 \pm 1.70$ & $3.31 \pm 1.86$ & $<.001$ & 0.30 \\
\hline It will give me a buzz & $4.21 \pm 1.99$ & $2.61 \pm 1.91$ & $<.001$ & 0.37 & $4.59 \pm 1.91$ & $4.01 \pm 2.00$ & $<.001$ & 0.14 \\
\hline It gives me a legal high & $3.30 \pm 1.91$ & $2.58 \pm 1.79$ & $<.001$ & 0.18 & $3.56 \pm 1.90$ & $3.17 \pm 1.90$ & .003 & 0.10 \\
\hline Physical benefits index $(\alpha=.79)$ & $3.74 \pm 1.58$ & $2.43 \pm 1.48$ & $<.001$ & 0.38 & $4.22 \pm 1.48$ & $3.50 \pm 1.57$ & $<.001$ & 0.22 \\
\hline \multicolumn{9}{|l|}{ Mental benefits } \\
\hline It will help me stay more focused & $2.49 \pm 1.43$ & $1.58 \pm 1.11$ & $<.001$ & 0.32 & $3.06 \pm 1.45$ & $2.21 \pm 1.33$ & $<.001$ & 0.28 \\
\hline I will feel more intellectual & $2.48 \pm 1.47$ & $1.48 \pm 1.00$ & $<.001$ & 0.34 & $2.95 \pm 1.54$ & $2.25 \pm 1.38$ & $<.001$ & 0.23 \\
\hline It will help me to think more clearly & $2.30 \pm 1.42$ & $1.49 \pm 1.03$ & $<.001$ & 0.29 & $2.81 \pm 1.48$ & $2.04 \pm 1.31$ & $<.001$ & 0.26 \\
\hline Mental benefits index $(\alpha=.87)$ & $2.43 \pm 1.28$ & $1.52 \pm 0.92$ & $<.001$ & 0.35 & $2.94 \pm 1.31$ & $2.17 \pm 1.17$ & $<.001$ & 0.29 \\
\hline \multicolumn{9}{|l|}{ Social benefits } \\
\hline It will help me to meet a potential date & $2.43 \pm 1.52$ & $1.56 \pm 1.13$ & $<.001$ & 0.29 & $2.90 \pm 1.56$ & $2.20 \pm 1.45$ & $<.001$ & 0.22 \\
\hline I will be more social & $3.42 \pm 1.82$ & $2.12 \pm 1.61$ & $<.001$ & 0.34 & $4.04 \pm 1.71$ & $3.11 \pm 1.79$ & $<.001$ & 0.24 \\
\hline It will help me to make new friends & $3.23 \pm 1.75$ & $2.18 \pm 1.63$ & $<.001$ & 0.28 & $3.84 \pm 1.71$ & $2.93 \pm 1.68$ & $<.001$ & 0.25 \\
\hline Social benefits index $(\alpha=.86)$ & $3.03 \pm 1.49$ & $1.95 \pm 1.29$ & $<.001$ & 0.34 & $3.59 \pm 1.42$ & $2.75 \pm 1.44$ & $<.001$ & 0.27 \\
\hline \multicolumn{9}{|l|}{ Recreation } \\
\hline I will have fun & $4.77 \pm 1.80$ & $2.60 \pm 1.81$ & $<.001$ & 0.27 & $5.44 \pm 1.54$ & $4.43 \pm 1.84$ & $<.001$ & 0.27 \\
\hline It will help me to pass the time & $3.91 \pm 1.93$ & $2.36 \pm 1.78$ & $<.001$ & 0.21 & $4.48 \pm 1.73$ & $3.62 \pm 1.96$ & $<.001$ & 0.21 \\
\hline Recreation benefits index $(\alpha=.79)$ & $4.34 \pm 1.64$ & $2.48 \pm 1.63$ & $<.001$ & 0.27 & $4.96 \pm 1.33$ & $4.03 \pm 1.69$ & $<.001$ & 0.27 \\
\hline \multicolumn{9}{|l|}{ Cultural benefits } \\
\hline It reinforces my culture & $2.07 \pm 1.47$ & $1.41 \pm 1.00$ & $<.001$ & 0.23 & $2.51 \pm 1.67$ & $1.85 \pm 1.31$ & $<.001$ & 0.21 \\
\hline It will bring my family together & $1.88 \pm 1.34$ & $1.26 \pm 0.78$ & $<.001$ & 0.25 & $2.29 \pm 1.51$ & $1.67 \pm 1.19$ & $<.001$ & 0.22 \\
\hline Cultural beliefs index $(\alpha=.73)$ & $1.98 \pm 1.24$ & $1.33 \pm 0.78$ & $<.001$ & 0.27 & $2.40 \pm 1.38$ & $1.76 \pm 1.11$ & $<.001$ & 0.26 \\
\hline \multicolumn{9}{|l|}{$\begin{array}{l}\text { Health consequences: If I were to smoke } \\
\text { a hookah }\end{array}$} \\
\hline It will give me a headache & $3.51 \pm 1.83$ & $4.00 \pm 2.17$ & $<.001$ & -0.12 & $3.31 \pm 1.67$ & $3.62 \pm 1.90$ & .01 & -0.08 \\
\hline It makes me dizzy & $3.79 \pm 1.85$ & $3.90 \pm 2.02$ & .32 & $\mathrm{~ns}$ & $3.72 \pm 1.74$ & $3.84 \pm 1.91$ & .33 & ns \\
\hline It makes me short of breath & $3.03 \pm 1.75$ & $4.06 \pm 2.11$ & $<.001$ & -0.25 & $2.93 \pm 1.61$ & $3.09 \pm 1.82$ & .17 & ns \\
\hline It makes my chest hurt & $2.72 \pm 1.69$ & $4.01 \pm 2.08$ & $<.001$ & -0.32 & $2.59 \pm 1.57$ & $2.79 \pm 1.75$ & .08 & ns \\
\hline It makes me cough & $3.48 \pm 1.89$ & $4.40 \pm 2.11$ & $<.001$ & -0.22 & $3.33 \pm 1.77$ & $3.57 \pm 1.95$ & .062 & $\mathrm{~ns}$ \\
\hline I will become addicted & $1.91 \pm 1.33$ & $3.22 \pm 2.06$ & $<.001$ & -0.36 & $1.94 \pm 1.34$ & $1.89 \pm 1.33$ & .64 & $\mathrm{~ns}$ \\
\hline I will get lung cancer & $3.55 \pm 1.68$ & $3.94 \pm 1.99$ & .002 & -0.10 & $3.49 \pm 1.63$ & $3.59 \pm 1.70$ & .37 & ns \\
\hline I will get an infectious disease & $2.59 \pm 1.59$ & $3.00 \pm 1.93$ & $<.001$ & -0.11 & $2.52 \pm 1.49$ & $2.63 \pm 1.64$ & .34 & $\mathrm{~ns}$ \\
\hline Health consequences index $(\alpha=.88)$ & $3.09 \pm 1.04$ & $3.64 \pm 1.48$ & $<.001$ & -0.21 & $3.05 \pm 0.98$ & $3.11 \pm 1.07$ & .40 & ns \\
\hline
\end{tabular}

ences in those who reported not ever trying waterpipes as compared with those having tried even 1 or 2 puffs and also between current users of waterpipes as compared with those who only tried 1 or 2 puffs.

Statistically significant increases were found in eversmokers versus never-smokers with regard to positive beliefs, such as physical benefits, mental benefits, social benefits, and recreation benefits. The same was found to be true when assessing current smokers versus those who had tried a waterpipe but had not done so in the past $30 \mathrm{~d}$. Of these categories, physical benefits had a greater effect on ever-smokers $(r=0.38)$ compared with mental benefits having the greatest effect on current smokers $(r=0.29)$.

Endorsement of health consequences as a belief was statistically significantly higher in never-smokers compared with ever-smokers, except for the variable "it makes me dizzy," which showed no statistical significance $(P=.42)$. Effect sizes were highest for "hookah helps me relax and relieve my stress" $(\mathrm{r}=0.39)$, "I will become addicted" $(\mathrm{r}=-.36)$, and "it will give me a buzz" $(\mathrm{r}=0.37)$. When comparing current smokers versus those who had ever tried waterpipe tobacco smoking, but had not done so in 
the past 30 days, only one of the 9 variables assessing health consequences was found to be statistically significant. This variable included "it will give me a headache" $(P=.02)$. The greatest effect was noted on the variable "hookah helps me relax and relieve my stress" $(\mathrm{r}=0.30)$.

\section{Discussion}

The present study indicated that waterpipe tobacco smoking rates in college students are not waning, suggesting that the college years may represent a vulnerable life stage for the initiation and continuation of waterpipe tobacco smoking. A study assessing female college freshmen noted an increase in pre-college use, suggesting that the behavior is starting at a younger age. ${ }^{28}$ This study represents eversmoker rates of $64 \%$ of the sample and current smoker rates of $34 \%$ of the sample. Other college studies have indicated varying rates of current smoking (6-22\%). ${ }^{33-37}$

One possible explanation is an increased awareness of alternative tobacco products during this stage in life as a factor in uptake as well as a continued trend from the increasing rates of waterpipe smoking noted in high school students. ${ }^{38,39}$ Clearly, national data suggest that $18-24-y-$ olds have higher prevalence rates than other adult age groups. ${ }^{40}$ The National College Health Assessment indicated ever-use rates of $30.5 \%,{ }^{21}$ whereas our data suggest higher ever-smoker rates of $64 \%$. Concerns are increased with other data suggesting that current alcohol and marijuana use is significantly higher in ever-smokers and current smokers as compared with never-smokers. ${ }^{41}$

There are differences in age trends between ever-smokers and current waterpipe smokers. In particular, our data suggest an increasing percentage of students reporting having ever tried waterpipe tobacco smoking (ever-smokers) as their age increases compared with current waterpipe smokers, whose percentage rates remain relatively stable after 18-19 y of age. To the best of our knowledge, no representational breakdown of age trending between eversmokers and current smokers in these vulnerable years has been reported to date in the literature. Previous studies have only documented increased usage in current smokers with freshmen or those who are younger in age. $21,35,42,43$ A concern cited often is the correlation between traditional cigarette use and current waterpipe tobacco smoking. ${ }^{35,43}$ Only sex differences in college data sets with waterpipe tobacco smoking have previously been recorded. ${ }^{30,44}$

Ward et $\mathrm{a}^{45}$ suggest that waterpipe tobacco smoking prevalence is not homogeneous between cities. Our data suggest that even within the same city, waterpipe tobacco smoking may be characteristically different as noted in the demographics and whether the participants are current waterpipe tobacco smokers or waterpipe tobacco ever-smokers. Further, our data suggest that there are observable differences between those who are current waterpipe tobacco smokers and waterpipe tobacco ever-smokers regarding demographic variables. In particular, Hispanics represent a larger proportion of ever-smokers than current smokers in our sample. The cultural aspect of waterpipe tobacco smoking may account for the high percentage within Muslim students who were smokers in both the current and ever-smoker groups. The data were consistent with other studies indicating an increased prevalence of waterpipe tobacco smoking in males as compared with females. ${ }^{21,43}$

Previous studies have indicated that students have a positive attitude regarding waterpipe tobacco smoking with positive perceptions leading to intention. ${ }^{46}$ Our results suggest that specific hookah-related beliefs pertaining to the physical, mental, recreational, and cultural benefits of waterpipe tobacco smoking are correlates of positive attitudes toward waterpipe tobacco smoking, whereas beliefs about the negative health consequences of waterpipe tobacco smoking are negatively correlated with attitudes. The associations between hookah-related beliefs and attitudes were maintained after controlling for demographic characteristics and smoking behaviors. Our study is similar to another college study in which it was found that attitudes had a larger correlation with intentions than did subjective norm. ${ }^{31}$ In addition, Sidani et $\mathrm{al}^{47}$ found that positive attitudes are strongly associated with the initiation of waterpipe tobacco smoking. It has been suggested elsewhere that interventions should focus on the negative consequences of waterpipe tobacco smoking for behavioral change campaigns. ${ }^{46}$

Our regression findings from the current study can help in designing effective behavioral interventions. For example, demographic characteristics explained a small percentage of the variance in both hookah attitudes and subjective norms; however, previous smoking behaviors (ie, smoking cigarette and/or waterpipe) explained a sizable percentage of these variances. The variance explained by previous behavior was nearly twice as large for attitudes as it was for subjective norms. Similarly, beliefs about the benefits and consequences of waterpipe tobacco smoking explained a larger proportion of the variance in attitudes than in subjective norms, suggesting that much of the covariance in subjective norms was not modeled in the current investigation. Our models did highlight the importance of several beliefs associated with attitudes and subjective norms. These findings indicate that beliefs are important in predicting precursors to waterpipe tobacco smoking intention and should be addressed in social marketing campaigns to deter use.

Finally, we assessed the beliefs for differences between waterpipe non-smokers and ever-smokers. Common beliefs have been reported, but there has not yet been a thorough assessment of differences between subgroups of 
waterpipe smokers based on frequency of use. ${ }^{11}$ We found that health consequences were probably the main barrier preventing nonsmokers from partaking in the behavior. Further, support for interventions that help to educate college students about the negative effects of waterpipe tobacco smoking are needed. Studies have highlighted the misperceptions of health consequences of waterpipe tobacco smoking that need to be corrected in intervention messages. ${ }^{11,41,48}$ The negative effects of waterpipe tobacco smoking have not affected waterpipe tobacco smoking rates in the same manner as has occurred with traditional smoking, ${ }^{35,37}$ probably due to a dearth of messages reaching the target audience. Limitations of the current study are that the findings represent self-report, using a cross-sectional design, and include data collected from one university in a southeastern state of the United States. Therefore, the results may not be generalizable to a larger population. Additionally, a limitation is the low response rate. We are unable to account for the beliefs and the behaviors of those who did not take the survey.

\section{Conclusions}

Waterpipe tobacco smoking continues to be a public health concern in the United States, especially among college students. Our study was a cross-sectional study of college students at one university. The scope of our study was to better understand the predictors of waterpipe tobacco smoking using the theory of reasoned action as a model. Our study fills a gap in the literature by looking at differences between those individuals who have tried waterpipe tobacco but have not smoked it in the past $30 \mathrm{~d}$ (ever-smokers) and those who have smoked it in the past $30 \mathrm{~d}$ (current smokers). These data can help in developing campaigns targeted at these different subgroups. Further research is needed to examine differences between early and later years of college use to determine whether campaigns to deter use may need to be tailored by the number of years in college. In addition, future research could look further into the "other" ethnic category for demographic variations. Our study, as well as the National College Health Assessment, found that the "other" category had high rates of waterpipe tobacco smoking. ${ }^{49}$ Although national data suggest that interventions should target students attending colleges in the west, our study indicates that this may not be an advisable blanket statement, and more specific data per campus or specific location/population may better inform interventions. Our data suggest that interventions and prevention messaging, such as educational flyers, are needed around the country in the geographic locations where waterpipe tobacco smoking is a growing health hazard. Hospitals and clinics are prime locations to reach individuals who may be showing early signs and symptoms of the negative health consequences of hookah smok- ing. Respiratory therapists are key stakeholders in understanding the behavior and educating their patients and the community.

\section{REFERENCES}

1. Martinasek MP, McDermott RJ, Martini L. Waterpipe (hookah) tobacco smoking among youth. Curr Probl Pediatr Adolesc Health Care 2011;41(2):34-57.

2. Ali AY, Safwat T, Onyemelukwe G, Otaibi MA, Amir AA, Nawas YN, et al. Smoking prevention and cessation in the Africa and Middle East region: a consensus draft guideline for healthcare providers: executive summary. Respiration 2012;83(5):423-432.

3. Alzoubi KH, Khabour OF, Azab M, Shqair DM, Shihadeh A, Primack B, Eissenberg T. CO exposure and puff topography are associated with Lebanese waterpipe dependence scale score. Nicotine Tob Res 2013;15(10):1782-1786.

4. Khabour OF, Alzoubi KH, Eissenberg T, Mehrotra P, Azab M, Carroll $\mathrm{MV}$, et al. Waterpipe tobacco and cigarette smoking among university students in Jordan. Int J Tuberc Lung Dis 2012;16(7):986992.

5. Maziak W. The waterpipe: an emerging global risk for cancer. Cancer Epidemiol 2013;37(1):1-4.

6. Maziak W, Eissenberg T, Ward KD. Patterns of waterpipe use and dependence: implications for intervention development. Pharmacol Biochem Behav 2005;80(1):173-179.

7. Nakkash R, Khalil J. Health warning labeling practices on narghile (shisha, hookah) waterpipe tobacco products and related accessories. Tob Control 2010;19(3):235-239.

8. Pascale S, Zeina AB, Mirna W. Saliva cotinine and exhaled carbon monoxide in real life waterpipe smokers: a post hoc analysis. Tobacco Use Insights 2009;2:1-10.

9. Alzyoud S, Kheirallah KA, Weglicki LS, Ward KD, Al-Khawaldeh A, Shotar A. Tobacco smoking status and perception of health among a sample of Jordanian students. Int J Environ Res Public Health 2014;11(7):7022-7035.

10. Noonan D, Kulbok P, Yan G. Intention to smoke tobacco using a waterpipe among students in a southeastern US college. Public Health Nurs 2011;28(6):494-502.

11. Noonan D, Kulbok PA. Beliefs and norms associated with smoking tobacco using a waterpipe among college students. J Addict Nurs 2012;23(2):123-128.

12. Noonan D, Patrick ME. Factors associated with perceptions of hookah addictiveness and harmfulness among young adults. Subst Abus 2013;34(1):83-85.

13. Nuzzo E, Shensa A, Kim KH, Fine MJ, Barnett TE, Cook R, Primack BA. Associations between hookah tobacco smoking knowledge and hookah smoking behavior among US college students. Health Educ Res 2013;28(1):92-100.

14. Primack BA, Walsh M, Bryce C, Eissenberg T. Water-pipe tobacco smoking among middle and high school students in Arizona. Pediatrics 2009;123(2):e282-e288.

15. Akl EA, Jawad M, Lam WY, Co CN, Obeid R, Irani J. Motives, beliefs and attitudes towards waterpipe tobacco smoking: a systematic review. Harm Reduct J 2013;10:12.

16. Hoek J, Maubach N, Stevenson R, Gendall P, Edwards R. Social smokers' management of conflicted identities. Tob Control 2013; 22(4):261-265.

17. Eng TR, Maxfield A, Patrick K, Deering MJ, Ratzan SC, Gustafson $\mathrm{DH}$. Access to health information and support: a public highway or a private road? JAMA 1998;280(15):1371-1375.

18. Fox S. Internet: health Pew internet and American life project. http:// www.pewinternet.org/fact-sheets/health-fact-sheet/. Accessed August 15, 2015. 


\section{Hookah Smoking Among College Students}

19. Primack BA, Shensa A, Kim KH, Carroll MV, Hoban MT, Leino EV, et al. Waterpipe smoking among U.S. university students. Nicotine Tob Res 2013;15(1):29-35.

20. Jackson D, Aveyard P. Waterpipe smoking in students: prevalence, risk factors, symptoms of addiction, and smoke intake: evidence from one British university. BMC Public Health 2008;8:174.

21. Primack BA, Hopkins M, Hallett C, Carroll MV, Zeller M, Dachille $\mathrm{K}$, et al. US health policy related to hookah tobacco smoking. Am J Public Health 2012;102(9):e47-e51.

22. Meganck S, Quarforth S, Messner M, Sherman S. From web to mobile: a meta-analysis of trends in digital health communication research, 2001-2010. Proceedings of the 15th International Public Relations Research Conference Miami, FL: March 8-10, 2011.

23. Thackeray R, Neiger BL, Hanson CL, McKenzie JF. Enhancing promotional strategies within social marketing programs: use of web 2.0 social media. Health Promot Pract 2008;9(4):338-343.

24. Gray NJ, Klein JD, Noyce PR, Sesselberg TS, Cantrill JA. Health information-seeking behaviour in adolescence: the place of the internet. Soc Sci Med 2005;60(7):1467-1478.

25. Liu BF, Jin Y, Briones R, Kuch B. Managing turbulence in the blogosphere: evaluating the blog-mediated crisis communication model with the American Red Cross. J Public Relat Res 2012;24(4): 353-370.

26. Al-Haddad N, Hamadeh RR. Smoking among secondary-school boys in Bahrain: prevalence and risk factors. East Mediterr Health J 2003; 9(1):78-86.

27. Jamil H, Templin T, Fakhouri M, Rice VH, Khouri R, Fakhouri H, et al. Comparison of personal characteristics, tobacco use, and health states in Chaldean, Arab American, and non-Middle Eastern White adults. J Immigr Minor Health 2009;11(4):310-317.

28. Fielder RL, Carey KB, Carey MP. Prevalence, frequency, and initiation of hookah tobacco smoking among first-year female college students: a one-year longitudinal study. Psychol Addict Behav 2012; 26(4):963-968.

29. Ajzen I, Fishbein M, editors. Understanding attitudes and predicting social behavior. New York: Prentice Hall; 1980.

30. Noonan D. A descriptive study of waterpipe smoking among college students. J Am Acad Nurse Pract 2013;25(1):11-15.

31. Martinasek MP, McDermott RJ, Bryant CA. Antecedents of university students' hookah smoking intention. Am J Health Behav 2013; 37(5):599-609.

32. SAS. Business Analytic Software. 2015. https://www.sas.com/en_us/ home.html. Accessed March 15, 2015.

33. Heinz AJ, Giedgowd GE, Crane NA, Veilleux JC, Conrad M, Braun $\mathrm{AR}$, et al. A comprehensive examination of hookah smoking in college students: use patterns and contexts, social norms and attitudes, harm perception, psychological correlates and co-occurring substance use. Addict Behav 2013;38(11):2751-2760.

34. Primack BA, Fertman CI, Rice KR, Adachi-Mejia AM, Fine MJ. Waterpipe and cigarette smoking among college athletes in the United States. J Adolesc Health 2010;46(1):45-51.
35. Eissenberg T, Ward KD, Smith-Simone S, Maziak W. Waterpipe tobacco smoking on a U.S. College campus: prevalence and correlates. J Adolesc Health 2008;42(5):526-529.

36. Grekin ER, Ayna D. Argileh use among college students in the United States: an emerging trend. J Stud Alcohol Drugs 2008;69(3): 472-475.

37. Smith-Simone S, Maziak W, Ward KD, Eissenberg T. Waterpipe tobacco smoking: knowledge, attitudes, beliefs, and behavior in two US samples. Nicotine Tob Res 2008;10(2):393-398.

38. Regan AK, Dube SR, Arrazola R. Smokeless and flavored tobacco products in the US: 2009 Styles survey results. Am J Prev Med 2012;42(1):29-36.

39. Florida Youth Tobacco Survey (FYTS). http://www.floridahealth. gov/statistics-and-data/survey-data/fl-youth-tobacco-survey/ _documents/2015-state/index.html. Accessed August 20, 2015.

40. Salloum RG, Thrasher JF, Kates FR, Maziak W. Water pipe tobacco smoking in the United States: findings from the National Adult Tobacco Survey. Prev Med 2015;71:88-93.

41. Villanti AC, Cobb CO, Cohn AM, Williams VF, Rath JM. Correlates of hookah use and predictors of hookah trial in US young adults. Am J Prev Med 2015;48(6):742-746.

42. Dugas E, Tremblay M, Low NC, Cournoyer D, O'Loughlin J. Waterpipe smoking among North American youths. Pediatrics 2010;125(6): 1184-1189.

43. Sutfin EL, McCoy TP, Reboussin BA, Wagoner KG, Spangler J, Wolfson M. Prevalence and correlates of waterpipe tobacco smoking by college students in North Carolina. Drug Alcohol Depend 2011; 115(1):131-136.

44. Braun RE, Glassman T, Wohlwend J, Whewell A, Reindl DM. Hookah use among college students from a midwest university. J Community Health 2012;37(2):294-298.

45. Ward KD, Eissenberg T, Gray JN, Srinivas V, Wilson N, Maziak W. Characteristics of U.S. waterpipe users: a preliminary report. Nicotine Tob Res 2007;9(12):1339-1346.

46. Barnett TE, Smith T, He Y, Soule EK, Curbow BA, Tomar SL, McCarty C. Evidence of emerging hookah use among university students: a cross-sectional comparison between hookah and cigarette use. BMC Public Health 2013;13:302.

47. Sidani JE, Shensa A, Primack BA. Substance and hookah use and living arrangement among fraternity and sorority members at US colleges and universities. J Community Health 2013;38(2):238245 .

48. Aljarrah K, Ababneh ZQ, Al-Delaimy WK. Perceptions of hookah smoking harmfulness: predictors and characteristics among current hookah users. Tobacco Induced Diseases 2009;5(1):16.

49. Haider MR, Salloum RG, Islam F, Ortiz KS, Kates FR, Maziak W. Factors associated with smoking frequency among current waterpipe smokers in the United States: findings from the national college health assessment II. Drug Alcohol Depend 2015;153:359-363. 